\title{
Estimating the Wind Resource in an Urban Area: a Case Study of Micro Wind Generation Potential in Dublin, Ireland
}

\author{
Keith Sunderland \\ keith.sunderland@tudublin.ie \\ Gerald Mills \\ University College Dublin, gerald.mills@ucd.ie \\ Michael Conlon \\ Technological University Dublin, michael.conlon@tudublin.ie
}

Follow this and additional works at: https://arrow.tudublin.ie/engscheleart2

Part of the Civil and Environmental Engineering Commons, and the Other Engineering Commons

\section{Recommended Citation}

Sunderland K. M., Mills G., and Conlon M. F, "Estimating the wind resource in an urban area: A case study of micro-wind generation potential in Dublin, Ireland," Journal of Wind Engineering and Industrial Aerodynamics, vol. 118, pp. 44-53, 2013. doi:10.1016/j.jweia.2013.04.002

This Article is brought to you for free and open access by the School of Electrical and Electronic Engineering at ARROW@TU Dublin. It has been accepted for inclusion in Articles by an authorized administrator of ARROW@TU Dublin. For more information, please contact arrow.admin@tudublin.ie, aisling.coyne@tudublin.ie, gerard.connolly@tudublin.ie.

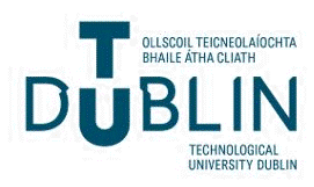




\title{
ESTIMATING THE WIND RESOURCE IN AN URBAN AREA: A CASE STUDY OF MICRO WIND GENERATION POTENTIAL IN DUBLIN, IRELAND.
}

\begin{abstract}
The micro-turbine wind market in cities faces significant challenges due to the complexities associated with the urban terrain but, if a renewable solution to increasing energy demand is to be achieved, energy conversion systems where populations are concentrated, that is cities, must be considered. This research evaluates the urban wind resource by employing a physically-based empirical model to link wind observations at a conventional meteorological site to those acquired at urban sites. The approach is based on urban climate research that has examined the effects of varying surface roughness on the wind-field between and above buildings. Here, this is applied to link observations at Dublin Airport, outside the urban area, to those made at an urban and suburban site in Dublin where instruments were placed near roof-level and well above roof height. The log model to describe the vertical wind profile is tested against observations made over the course of a year. It is shown to have sufficient accuracy to assess the potential for micro-turbine energy generation in cities and illustrates that the urban wind resource can be evaluated from measurements made at a nearby site, adjusted for the urban site location.
\end{abstract}

\section{Highlights}

- The article investigates if a viable wind resource, worth exploiting, exists at an accessible height above a city (Dublin, Ireland)

- Urban climatology and the simple logarithmic profile, are employed to successfully extrapolate the wind resource at the city Airport into an associated suburban and urban location, to a height between 1.5 and 2 times the respective average building height at both locations

- The analysis shows that in conjunction with urban surface roughness, the urban frictional velocity must also be considered for urban wind resource modelling

- Other models are utilised to investigate the nature of the wind resource below the recognised lower limit of the logarithmic profile, namely the power law and a methodology primarily developed for urban air pollution modelling

- The research is provided a renewable energy context by considering the productivity of a commercially available wind generator. The results show that the wind resource available at roughly twice the average building height at either an urban and suburban location is worth harnessing, but within a very short height reduction, the wind resource depletion renders the consideration economically unviable.

\section{Key Words}

Urban wind resource, log wind profile, micro wind generation.

\section{Authors:}

Keith Sunderland, Dublin Institute of Technology (keith.sunderland@dit.ie)

Gerald Mills, University College Dublin (gerald.mills@ucd.ie)

Michael Conlon, Dublin Institute of Technology (michael.conlon@dit.ie)

\section{Corresponding Author}

Keith Sunderland

School of Electrical Engineering Systems, Dublin Institute of Technology, Dublin 8, Ireland

ph: +353-1-4024882 


\section{Introduction}

Over the last few decades there have been changes in the scale and nature of energy generation with the development of microgeneration technology that is based on renewable energy sources, such as solar and wind power. Here, microgeneration is defined as a source of electrical energy and all associated equipment that operates in parallel with a conventional distribution network and is rated up to and including $25 \mathrm{~A}$ at low voltage (230V, single phase) and $16 \mathrm{~A}$ at low voltage $(230 / 400 \mathrm{~V}$, three-phase) (CENELEC, 2007). Typically, these consist of arrays of photovoltaic cells or wind turbines that are positioned on or adjacent to a dwelling or business premise employed as a supplementary energy source. Increasingly these technologies form part of the energy mix in many economies and represent an important component of environmental strategies aimed at reducing Carbon Dioxide emissions. The (dis)advantage of these technologies is their size, which allows energy to be generated at multiple sites (close to the point of consumption) but makes it difficult to integrate with existing energy generation/distribution systems. Few of these are located in urban settings where demand is greatest and they could provide an alternative to centralised generation using fuels that generate carbon emissions (Ayhan and Sağlam, 2012). However, the integration of renewable energy technologies into the urban form is ideally done at the planning and design stages of urban development, before decisions are taken that either diminishes the resource or our capacity to avail of it (OJEU, 2010; Department of Environment, 2011). This is particularly true for the wind resource which is greatly affected by the nature of urban development itself, including the dimensions of individual buildings and their layout. Despite the challenges, the concentration of population in urban areas provides an opportunity for micro-energy generation close to where this energy is used. Even where the urban form is established, guidelines on the potential for exploiting the urban resource are largely absent. This paper considers the opportunities for microgeneration using wind turbines in urban areas, where the demand is greatest but the effect of urbanisation has been to diminish the available resource.

The micro-turbine wind market in cities faces significant challenges due to the complexities associated with the urban terrain but, if a renewable solution to increasing energy demand is to be achieved, energy conversion systems where populations are concentrated must be considered. There is significant research assessing the wind energy resource in 'rural' locations around the world (Islam et al., 2011, Cabello and Orza, 2010, Fyrippis et al., 2010) and this research has fed into assessing the potential for wind energy conversion systems using micro/small-turbines (Kavak Akpinar and Akpinar, 2005, Jowder, 2009). However, some of the research on urban locations focuses on the performance of turbines (Encraft., 2008, EST, 2009) rather than the available wind resource. As a result, the literature provides little guidance to the exposure of turbines in urban settings to achieve the stated performance. In this paper, the wind resource over two distinct urban surfaces is examined by comparison with that available at a nearby non-urban site. The differences between sites are related to the morphology of the urban terrain using methodologies that have been developed for micrometeorological purposes, chiefly with respect to urban air quality.

\section{Literature Review}

Wind turbines extract kinetic energy from moving air, converting it into mechanical energy via the turbine rotor and then into electrical energy through the generator:

$$
P=\frac{C_{p} \cdot \rho \cdot A \cdot u^{3}}{2}
$$

where the mechanical output power $(\mathrm{P})$ is a function of the performance coefficient of the turbine $\left(C_{p}\right)$, the density of air $(\rho)$, the area swept by the turbine projected in the direction of the wind $(A)$ and wind-speed $(u)$. The two factors that regulate power then are the turbine technology and the 
wind resource. Note that power is proportional to the wind-speed raised to the power of three, so that small variations in $u$ can have a significant impact on $P$.

In the conversion of mechanical energy into usable electricity, aerodynamic conversion losses are high. According to the Betz limit, the maximum possible conversion coefficient of a wind rotor is $59.3 \%$. However in practice aerofoil blade roughness, wake effects, and hub and tip effects combined with the electricity conversion systems reduce the typical maximum efficiency of a wind rotor to $\approx 30 \%$ (Figure 1 ). Moreover, if the wind is unsteady the energy conversion capability of the wind rotor is degraded. The two properties that distinguish a specific turbine technology are its blade sweep area and its power curve. The former governs the amount of power that can be captured from the available wind on site while the latter describes its performance with varying wind speed. However, power curves are rarely tested in the field or independently verified (Peacock et al., 2008). The cumulative energy output of a generator is often presented as a capacity factor: the ratio of the measured turbine yield to the maximum output over a given time period. Establishing the capacity factor a priori is essential for calculating the economic return on investment in wind turbine technology. For example, in the UK the measured capacity ranges from $24 \%$ in Durham to $33 \%$ in Caithness, Orkney and Shetland (Peacock et al., 2008). To evaluate the capacity, knowledge of the wind resource is critical.

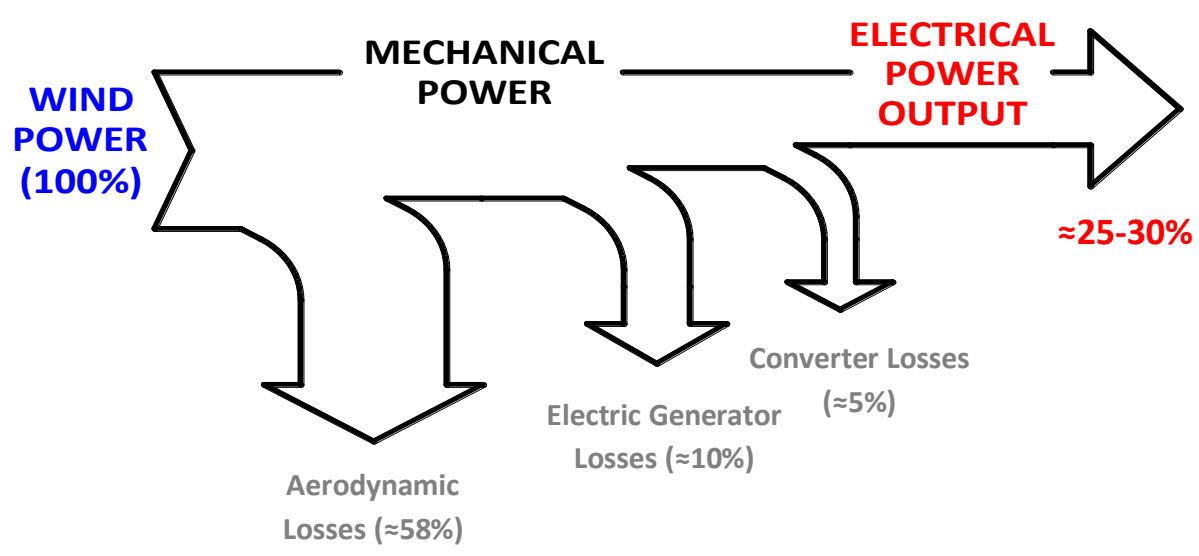

Figure 1: Flow of Power Conversion in a wind Turbine System. The aerodynamic conversion losses are significant and according to Betz's law, only $59.25 \%$ of the kinetic wind energy can be converted into mechanical power. This is a guideline figure and is generally much lower (due to blade roughness, hub loss, wake rotation, tip losses and electricity conversion systems).

There are many challenges to incorporating wind generation into urban areas. These include planning issues regarding noise and visual impact that are reflected in some planning legislation that effectively bars their deployment in residential areas (e.g. DOELG, 2007). Elsewhere, planning law is more permissive and their use in residential areas actively encouraged through tax breaks (Portal, 2011). It remains the case however that we know little of the wind resource in urban areas and that the capacity factor for a given urban installation is difficult to estimate, in the absence of site-specific measurements. This is because cities are aerodynamically rough and heterogeneous such that the windfield close to the urban 'surface' (that is, near rooftop height) is highly variable in space and time. Turbines close to this urban surface experience a highly localised wind environment that is has proved difficult to predict from measurements made elsewhere. Some researchers have used computational fluid dynamic modelling to ascertain the potential of building mounted turbines (e.g. Heath et al., 2007; Watson, 2007; Ayhan and Sağlam, 2012). This work has shown the sensitivity of energy output to turbine position and mounting height with regard to the building, such that small changes in location can have dramatic impacts on performance. However, this approach is of limited 
value for routine site evaluation which commonly estimates the wind resource at a site of interest from observations made at a nearby location, which are adjusted for the location of interest.

There are tools that can provide guidance at a regional scale. For example, the $\mu$-wind modelling software uses data from a number of sites across the UK to characterise the wind potential for wind turbine. The tool accounts for terrain roughness and height of turbine (Bahaj et al., 2007). There are also wind atlases which have been developed based using air flow models that account for the effects of topography and provide estimated wind speed at $10 \mathrm{~m}$ (and higher) above the surface at a horizontal scale of $1 \mathrm{~km}^{2}$ (e.g. NOABL, 2012). These techniques are useful for evaluating locations for wind farms where turbines are located in an exposed setting at a considerable height above the ground and its roughness elements (grass, crops or shrub). They are of limited use for microgeneration in cities where turbines are positioned at, or near, the heights of buildings. To address this, Millward-Hopkins et al (2011) employed large-scale wind speed climatology data bases such as the Numerical Objective Analysis of Boundary Layer (NOABL) database to predict wind speeds in typical urban and suburban areas using heterogeneous block arrays to estimate the effects of urban roughness. In other research deWit et al (2002) used a scaling factor to estimate wind close to rooftops based on observations taken at a standard meteorological site, located at a nearby Airport. Nevertheless, there remains a need for observations of wind speed close to urban rooftops to provide validation for model results (Heath et al, 2007).

A commonly employed means of assessing the wind available at an urban site is to use the log wind profile and extrapolate from a non-urban site to an urban site by modifying its parameters,

$$
u(z)=\frac{u_{*}}{\kappa} \ln \left(\frac{z-z_{d}}{z_{0}}\right)
$$

where $\mathrm{k}$ is von Karman's constant $(0.4), \mathrm{z}$ is height above the ground, $z_{0}$ is the roughness length and $z_{d}$ is the displacement height. The friction velocity $\left(u_{*}\right)$ is a measure of the shearing stress that drives the flux of momentum to the Earth's surface. This relationship describes wind-speed in the direction of airflow within a boundary layer where airflow has adjusted to the underlying surface. It is properly applied to extensive homogeneous surfaces (such as grass) under neutral atmospheric conditions and is valid under these circumstances to heights $(z)$ above $\left(z_{d}+z_{o}\right)$. Typical values for the roughness length are listed in Table 1.

Table 1: Davenport classification of effective terrain roughness (Oke T. R., 2006)

\begin{tabular}{|c|c|c|}
\hline $\begin{array}{l}\text { Roughness } \\
\text { Class }\end{array}$ & $\begin{array}{l}\text { Roughness } \\
\text { length }\left(z_{0}\right)\end{array}$ & Description of landscape \\
\hline Approx. Open & 0.1 & $\begin{array}{l}\text { Moderately open country with occasional obstacles (e.g. Isolated low buildings or } \\
\text { trees) at relative horizontal separations of at least } 20 \text { obstacle heights }\end{array}$ \\
\hline Rough & 0.25 & $\begin{array}{l}\text { Scattered obstacles (buildings) at relative distances of } 8 \text { to } 12 \text { obstacle heights for low } \\
\text { sold objects (e.g. buildings) }\end{array}$ \\
\hline Very rough & 0.5 & $\begin{array}{l}\text { Area moderately covered by low buildings at relative separations of } 3 \text { to } 7 \text { obstacle } \\
\text { heights and no high tress. }\end{array}$ \\
\hline Skimming & 1.0 & Densely bult-up area without much building height variation. \\
\hline Chaotic & 2.0 & City centres with mix of low and high-rise buildings (Analysis by wind tunnel advised) \\
\hline
\end{tabular}

The displacement height $\left(z_{d}\right)$ identifies the level of the aerodynamic surface where $u(z)$ (obtained from eq. (2)) goes to zero. Below this level is the Roughness sub-layer (RSL) where eq. (2) is no longer applicable. To use eq. (2) requires values for the friction velocity, the displacement height and the roughness length. These can be obtained from standard wind observations where instruments are positioned above an extensive short grass surface $\left(z_{0} \approx 0.1 \mathrm{~m}\right)$ in neutral conditions. In these 
circumstances, wind speed plotted against the log of height will be described by a straight line with an intercept at $z_{0}$ and $u_{*}$ can be obtained from its slope. The profile is not sensitive to the value for $z_{d}$, which is approximately equal to $2 / 3$ the average height of the surface roughness elements (essentially $0 \mathrm{~m}$ in the case of short grass).

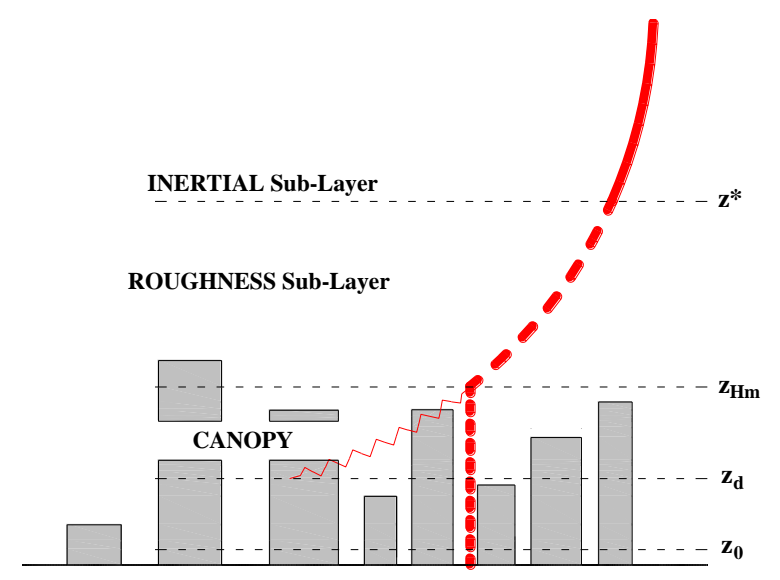

Figure 2: Urban Air-flow model in terms of the logarithmic model (eq. (2)). This profile performs well above $z^{*}$ and within the roughness sub-layer $\left(z^{*}<z>H_{m}\right)$ is less viable. This research will investigate alternative models within this boundary. Below $H_{m}$, generic wind speed models are less practicable as is the potential for wind turbines.

Wieringa (1986) proposed that the log profile could be employed to estimate wind at a site of interest (site $B$ ), based on observations made at a nearby reference site (site $A$ ),

$$
u_{z A}=u_{z B}\left(\frac{\ln \mathbf{C}_{r} / z_{0 B} \cdot \ln \boldsymbol{(}_{A} / z_{0 A}}{\left.\ln \mathbf{(}_{B} / z_{0 B} \cdot \ln \mathbf{(}_{r} / z_{0 A}\right)}\right)
$$

This formulation requires information on the roughness lengths at the respective sites and at a reference height $\left(z_{r}\right)$, which is sufficiently distant from the underlying surfaces that their distinct aerodynamic effects have been erased. In urban areas, it has been suggested that $z_{r}$ should be equal to four times the average height of the buildings $\left(z_{\mathrm{Hm}}\right)(\mathrm{Oke}, 2006)$. In the absence of observations made at each location, this scheme is dependent on the selection of appropriate roughness values for the surfaces. Although these can be retrieved from tables (e.g. Table 1), site specific information may be needed. In complex urban settings where surfaces are both rough and heterogeneous, the value of $z_{0}$ will depend on the obstacles encountered along the flow path, which may vary with wind direction. There are morphometric methods that evaluate $z_{0}$ based on the dimensions of buildings in the vicinity of the site of interest and the direction of wind (e.g. MacDonald et al, 1998, Raupach, 1994). Nevertheless, there are a few obstacles to using eq. (3) in an urban environment.

Firstly, the Wieranga formulation suggests that the friction velocities for the two sites are identical so that the difference in wind-speeds at any given height can be attributed to the effects of surface roughness. However, where the differences in $z_{0}$ between the sites is very large, as is the case when urban sites are compared to most rural sites, the value of $u_{*}$ must be adjusted. Bottema (1995) suggests (eq. (4)) that the urban value of $u_{*}$ can be estimated a from the ratio of the urban to rural roughness lengths. 


$$
\frac{u_{*(\text { urban })}}{u_{*(\text { rural })}}=\left(\frac{z_{0(\text { urban })}}{z_{0(\text { rural })}}\right)^{\beta}
$$

where $\beta$ has a value of 0.0706 based on research using an urban surface created from homogeneous building groups.

Secondly, although the log profile will estimate wind speed to the level of $z_{d}+z_{0}$, studies suggest that it is not applicable to a layer that extends above rooftop height where flow is not adjusted. Wind observations and modelling studies indicate that the roughness sub-layer (RSL) in cities extends from the ground to between two and four times the heights of buildings (i.e. 2. $z_{\mathrm{H}}$ to $4 . z_{\mathrm{Hm}}$ ). In the layer between the displacement height $\left(z_{d}\right)$ and the top of the RSL $\left(z^{*}\right)$ the friction velocity $\left(u_{*}\right)$ is no longer constant. As part of a COST Action to examine the application of meteorology to urban air pollution problems, particular attention was paid to estimating airflow in this layer (Fisher et al. 2005). Rotach et al. (2005) suggest that the friction velocity at any height $\left(u_{*}(z)\right)$ within the RSL above the displacement height (that is, from $d$ to $z^{*}$ ) may be parameterised against the value at the top of the RSL (which may be obtained from the log profile),

$$
\left(\frac{u_{*(z)}}{u_{*\left(z^{*}\right)}}\right)^{b}=\sin \left(\frac{\pi}{2}\left(\frac{z-z_{d}}{z^{*}-z_{d}}\right)\right)^{a}
$$

where $\mathrm{a}=1.28$ and $\mathrm{b}=3.0$. To use this scheme requires $u_{*_{\left(z^{*}\right)}}$ which is usually not available at the site of interest.

This COST approach was evaluated using wind observations acquired as part of the Basel UrBan Boundary Layer Experiment (BUBBLE) (Rotach et al. (2005)), which included instruments located within both urban and rural settings. The results showed that eq. (5) yields good results $( \pm 10 \%)$ for estimates of airflow at $z^{*}$ (that is, the top of the RSL) using friction velocity values obtained from urban observations. The results were markedly poorer when $u_{*}$ is estimated from rural observations using eq. (4), chiefly as a result of systematic underestimation. This is perhaps not surprising as this formulation assumes well adjusted profiles over two extensive surfaces of different roughness where the wind at the top of the boundary layer is constant (Bottema, 1997). In reality, the urban surface may consist of discrete 'patches' of land-cover subtypes such as residential suburbs, commercial warehouses, parks, business districts, etc. each of which has distinct roughness properties. Depending on wind direction the wind profile at a site will reflect the different surfaces airflow encountered on its passage. Rotach et al (2005) concluded that determining the height of the roughness sub-layer $\left(z^{*}\right)$ was the most problematic part of the COST procedure and that while their observations suggested $z^{*} \approx 1.55 z_{\mathrm{H}}$, further observational and modelling work in different urban settings was required. In summary then, the COST approach is: to employ the logarithmic profile to winds at heights above the RSL $\left(z \geq z^{*}\right)$, where $u_{*}$ is constant; estimate $u_{*}$ from eq. (4), if there are no local observations and; estimate wind speed within the RSL ( $z^{*}$ to $z_{d}$ ) using eq. (5) to derive the $u_{*\left(z^{*}\right)}$.

A alternative method is to estimate the wind speed within the RSL using a power law formulation,

$$
\frac{u_{(z)}}{u_{\left(z^{*}\right)}}=\left(\frac{z-z_{d}}{z^{*}-z_{d}}\right)^{\alpha}
$$

where, $\alpha$ is the wind shear exponent. Millward-Hopkins et al (2011) suggest that the value for $\alpha$ could be obtained by matching the log- and power-law profiles at a reference height $\left(z^{*}\right)$. 
The research reported on here evaluates wind speed close to roof-level in urban areas from the perspective of wind energy generation and the placement of micro-turbines. The evaluation is based on observations made at three sites in Dublin, one of which (Dublin Airport) represents a reference station that provides information on the 'background' wind climate. The correspondence between the wind resource at this site and that available at an urban and at a suburban site in Dublin is examined using the approaches discussed above. The implications for micro-energy generation based on current technology are then assessed.

\section{Methodology}

This research is based on wind observations made at three locations in Dublin. The reference site is located at the Airport (A), which is located on the margins of the city, $10 \mathrm{~km}$ from the city centre (Figure 3). The site conforms to the WMO standards for synoptic weather stations and is managed by Met Eireann, the Irish Meteorological Service. The wind records are used to represent the wind climate that would be present across the Dublin area in the absence of the city itself. The data employed here consists of wind speed and direction and the Pasquill-Gifford (PG) stability index at hourly intervals. The PG index classifies the thermal state of the atmosphere (from unstable to neutral to stable) based on wind speed, solar radiation receipt and cloud cover. These observations are typical of information that is commonly available to wind engineers throughout the world and from which extrapolations are made to a site of interest.

There are two other observation sites used in this research to represent two distinct urban landscapes. One is located close to the city centre in an area that has mixed residential, industrial and commercial uses. The buildings vary considerably in dimensions and there is comparatively little green space. The other is located in a mature, vegetated suburb, where the dimensions of the buildings are nearly uniform and the land use is residential in character. At each site there are two measurement platforms at different heights with regard to the urban surface. The high platform is at least 1.5 times the average height of buildings and the low platform is close to the rooftop height. Each of the stations is positioned within a broadly defined 'homogenous' landscape in the sense that the character of the surrounding urban morphology is similar in all directions. This is especially true of the suburban site.

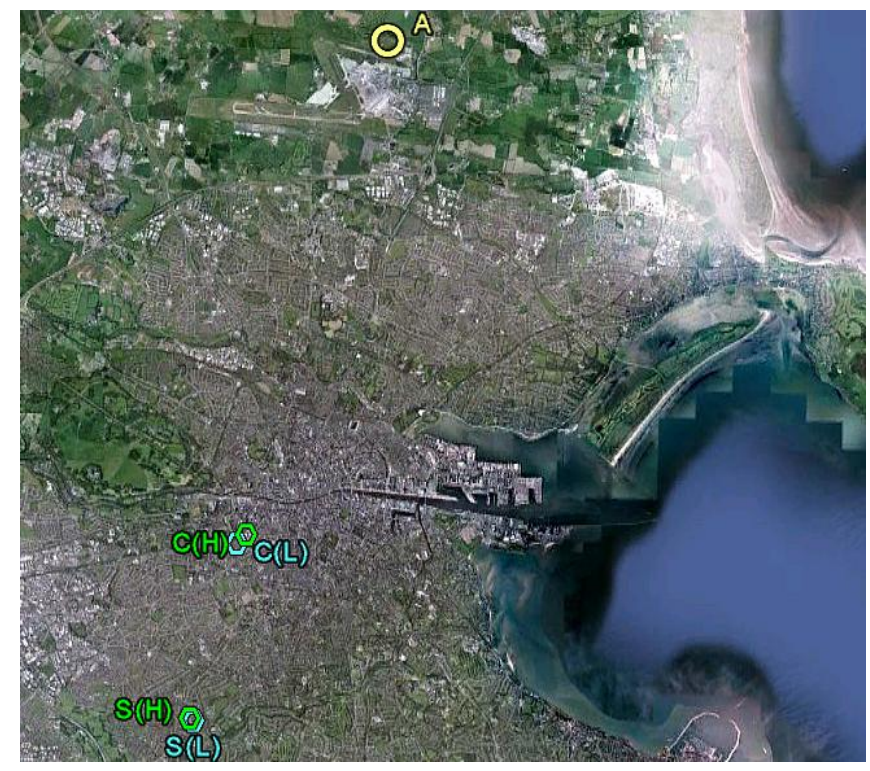

Figure 3: Satellite image of Dublin city, indicating the relative positions of the observation locations across Dublin City: (Background) Dublin Airport (A), Suburban Upper-platform $(\mathrm{S}(\mathrm{H})$ ), Suburban Low-platform $(\mathrm{S}(\mathrm{L}))$, Urban Upper-platform $(C(H))$ and Urban lower-platform (C(L)). (Google Earth, 2010) 


\subsection{Wind Observations}

Wind observations at the high platform for each site were made by Campbell Scientific sonic anemometers (CSAT 3D), which were employed as part of an eddy correlation study of the energy and carbon fluxes at the urban surface. These instruments record wind speed along three orthogonal axes at resolution of less than $1 \mathrm{~mm} / \mathrm{s}$ (Campbell-Scientific, 2011) and in this deployment were interrogated at $10 \mathrm{hz}$. The data was subsequently averaged to generate observations that were compatible with the Airport data. Observations at the lower platforms were made using inexpensive weather stations (DavisTM Vantage Vue) that utilise robust cup anemometers and simple vanes. The wind speed resolution is $0.1 \mathrm{~m} / \mathrm{s}$ and wind direction is recorded by compass sector (each $22.5^{\circ}$ wide). These instruments are interrogated every 15 minutes and the data was processed to yield halfhourly observations.

The suburban site $(\mathrm{S})$ is located within an extensive residential area consisting of area of two-storey houses with pitched roofs (6-7 m tall), significant greenspace and mature trees (Figure 4). The observation site is a one storey, flat-roofed school building. The high platform $\left(\mathrm{S}_{H}\right)$ is mounted on a mast on the roof at a height of $12 \mathrm{~m}$. The low platform $\left(\mathrm{S}_{\mathrm{L}}\right)$ is less than $30 \mathrm{~m}$ distant and is positioned at $5 \mathrm{~m}$. The city centre site $(\mathrm{C})$ is located within a mixed commercial/residential/industrial area. The buildings vary in size but are generally 2-3 storeys in height and there is little greenspace. Here, the high platform $\left(\mathrm{C}_{\mathrm{H}}\right)$ is positioned on an antenna on the roof of a three storey building at an elevation of $17 \mathrm{~m}$. Its higher position is consistent with the higher mean building height $\left(z_{H}\right)$ in the surrounding area. The low platform $\left(C_{L}\right)$ observations are made some $200 \mathrm{~m}$ away at an elevation of $8 \mathrm{~m}$ at the gable-end of a two-storey terraced house.

The observations at $\mathrm{C}_{\mathrm{H}}$ and $\mathrm{S}_{\mathrm{H}}$ are used here to represent the wind resource available near the top of the Roughness Sub-Layer (RSL), that is, at $z^{*}$. Those at the lower platforms $\left(C_{L}\right.$ and $\left.S_{L}\right)$ represent winds within the RSL.

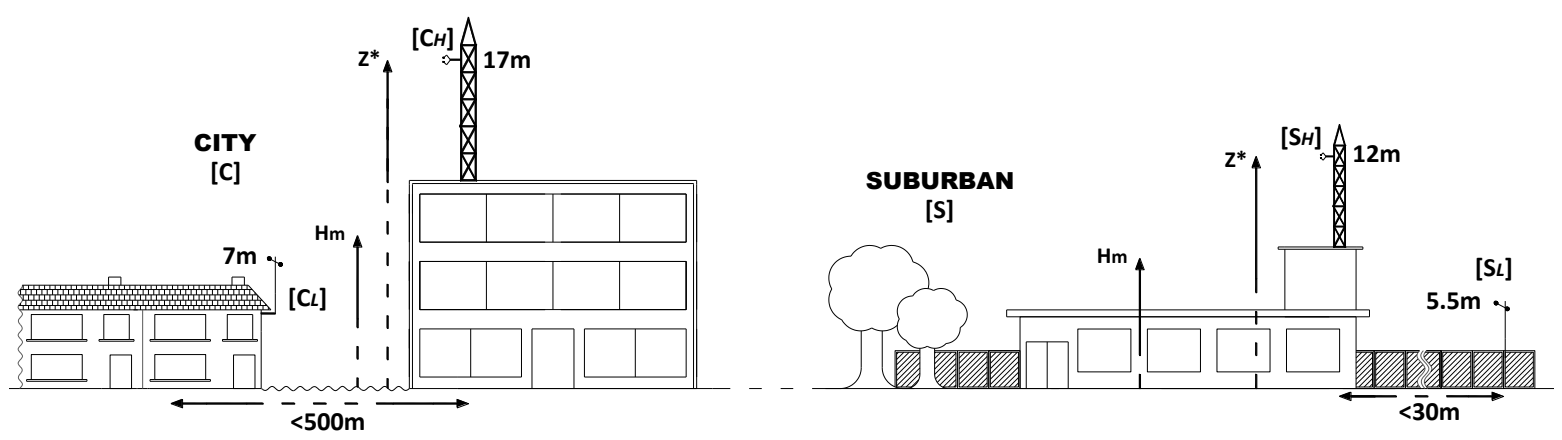

Figure 4: Relative context of wind observation locations. The city observations are within an environment characterised by terraced two storey buildings, with little or no vegetation and includes occasional office buildings of 2-4 storeys. The suburban location is characterised by semi-detached dwellings (two storeys) with considerable vegetation (trees) and is generally more spread-out than the urban location. The diagram further illustrates the relative position of the observation platforms and a $z^{*}$ estimation for both the urban and suburban locations.

\subsection{Estimating urban wind speed}

The observations at the airport site $(A)$ are used to derive estimates of the wind resource at both urban sites ( $C$ and $S$ ) using each of the approaches outlined in Section 2 (eqns. (2) to (5)). These estimates were then tested against the measured data at $C$ and $S$. The primary focus of this work is on wind at the top of the RSL $\left(\mathrm{u}_{2^{*}}\right)$ where turbine losses due to unsteady winds are minimized. The instrument at $\mathrm{C}_{\mathrm{H}}$ and $\mathrm{S}_{\mathrm{H}}$ are positioned at, or near, this level and may be used to evaluate different approaches. A secondary focus is on the loss of the wind resource within the RSL. For this analysis, 
we rely on the winds at $z^{*}$ to estimate the winds reported at $C_{L}$ and $S_{L}$ and to infer the wind profile of the RSL between $z^{*}$ and the close to rooftop height.

Hourly airport data for the period November 2010-2011 was used in these analyses. As each of the approaches used to estimate the wind resource is premised on the neutral log wind profile, those days classified as predominantly neutral (more than 15 hours categorised as $D$, according to the Pasquill-Gifford stability index) were included. The dominant wind direction at $\mathrm{A}$ under these conditions was south-westerly and wind directions varying from $120^{\circ}$ and $300^{\circ}$ from North on $82 \%$ of occasions were prioritised for analysis. Once gaps in data and erroneous records were considered, 6812 hours and 5905 hours of observational data respectively, were available at $C_{H}$ and $S_{H}$. A shorter period of just 718 hours was used for the comparisons of estimates with measured winds at the lower platforms, $\mathrm{C}_{\mathrm{L}}$ and $\mathrm{S}_{\mathrm{L}}$.

Initially, the background wind conditions for all the observation sites ( $A, C$ and $S$ ) is established by extrapolating (using (2)) from the airport site upwards to a height well above the surface roughness elements $\left(z_{r}\right)$, which here is set at $200 \mathrm{~m}$. The wind at this level $\left(u_{z r}\right)$ is then used to estimate the wind resource at the top of the RSL $\left(u_{z^{*}}\right)$, which is situated close to observations at $C_{H}$ and $S_{H}$ and then within the RSL, where we have observations at $C_{L}$ and $S_{L}$.

Three approaches are used here to estimate $u_{z^{*}}$ based on the log-wind profile (2)

1. Wieranga approach. In this formulation (3) the friction velocity $\left(u_{*}\right)$ is treated as constant over all sites and the wind speed at $\mathrm{C}_{\mathrm{H}}$ and $\mathrm{S}_{\mathrm{H}}$ uses $u_{*}$ from the Airport and the estimated roughness lengths for city centre and suburban landscapes, respectively (Table 1).

2. Bottema approach. The same procedure as above except $u_{*}$ is adjusted according to eq. (4).

3. In the log-fitting approach, $z_{0}$ and $u_{*}$ at each urban site is estimated by numerically fitting eq. eq. (2) to the observed data at $\mathrm{C}_{\mathrm{H}}$ and $\mathrm{S}_{\mathrm{H}}$, using the established values for $u$ at the reference height of $200 \mathrm{~m}$ as an upper boundary condition. This fitting is done by varying $u_{*}$ and $z_{0}$ in eq. (2) so as to minimise the error between estimated and measured wind at each site.

The results of these procedures are compared with the observations at both sites. Within the RSL (that is, $z<z^{*}$ ) the wind profile is estimated using $u_{z^{*}}$ obtained from the log wind profile as the upper boundary condition. Two techniques are used to generate wind estimates at height of the lower platforms $\left(C_{L}\right.$ and $\left.S_{L}\right)$ for which observations are available. In the first, the power law, eq. (6), is used and following Willard-Hopkins et al (2011), the wind shear exponent $(\alpha)$ is obtained by matching the gradients of the power and logarithmic profiles at $z^{*}$ through eq. (7).

$$
\alpha=\left(\ln \left(\frac{z-z_{d}}{z_{0}}\right)\right)^{-1}
$$

The second technique is based on COST (5), which allows the friction velocity to vary in the layer between the displacement height and the top of the RSL (that is, $z_{d} \leq z \leq z^{*}$ ). Inserting this into the log wind profile, eq. (2) yields

$$
u(z)=\frac{u_{*\left(z^{*}\right)}}{k} \int_{z=d}^{z=z^{*}} \frac{\sqrt[3]{\sin \left(\frac{\pi}{2} \cdot \frac{z-z_{d}}{z^{*}-z_{d}}\right)^{1.28}}}{\left(z-z_{d}\right)} d z
$$


A third technique is also presented in which the fitted logarithmic profile is utilised to establish $u_{*}\left(z^{*}\right)$ and then by variation of the parameters in eq. (5), the COST profile is essentially locked into the logarithmic profile at $z^{*}$. Figure 5 illustrates the profiles derived using these techniques and matching both the Power and Cost models to the logarithmic profile ${ }^{1}$.

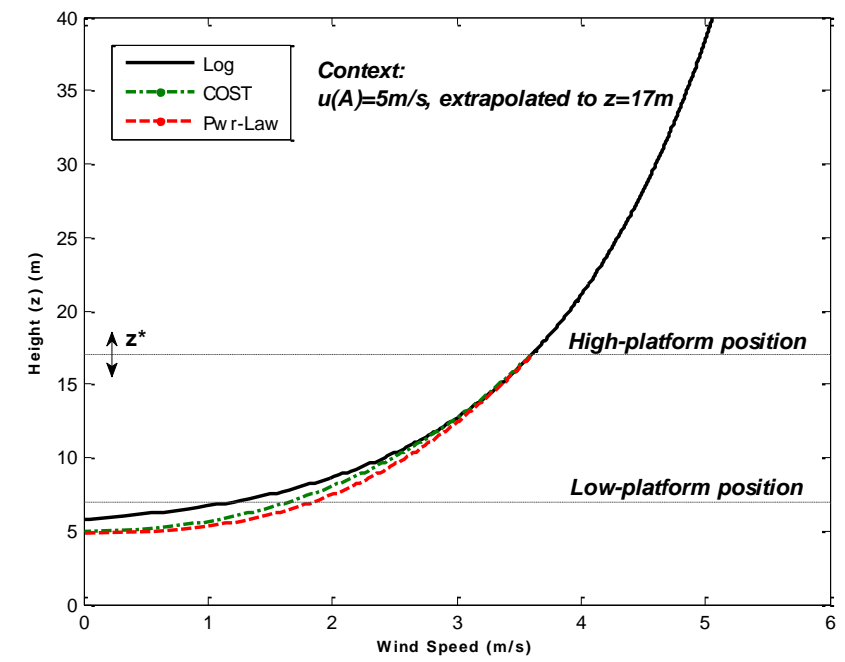

Figure 5: Roughness layer wind speed modelling employing the two methodologies (power law and COST air pollution model), matched to the logarithmic profile at the urban location (extrapolated from a $5 \mathrm{~m} / \mathrm{s}$ airport reference wind speed). With respect to the urban location, the high-platform observations are made at $17 \mathrm{~m}$ and with respect to the urban topography presented at this location, $z^{*}$ is considered also to be in the vicinity of $17 \mathrm{~m}$.

\section{Results}

Table 2 shows the wind climate over the study period for the Airport site. The statistics on the mean wind speed and direction (and their variability) are decomposed into $30^{\circ}$ sectors of the compass. The predominant direction of the airflow is south-westerly (over $80 \%$ of wind originates in the $120^{\circ}$ to $300^{\circ}$ part of the compass). The mean wind speed is $5.2 \mathrm{~m} / \mathrm{s}$ but the winds from south-west are closer to $6.0 \mathrm{~m} / \mathrm{s}$. The strongest winds $(7.4 \mathrm{~m} / \mathrm{s})$, which occur on $24 \%$ of occasions have a mean direction of $260^{\circ}$. The recorded wind is generally strong and steady: the standard deviations are less than $25 \%$ the value of the mean. Figure 6 shows the frequency distribution of the recorded wind speed in the sector $120^{\circ}$ to $300^{\circ}$, which is where the bulk of the wind resource lies. On the vast majority of occasions the atmosphere at the Airport is neutral $(86 \%)$ or slightly stable/unstable according to the Pasquill-Gifford index. On less than $4 \%$ of occasions is the atmosphere either stable or unstable. Consequently, the use of the log wind profile (eq. (2)), without adjustment for stability, is valid. To provide a context for what follows, the estimated wind speed $\left(\mathrm{u}_{\mathrm{z}}\right)$ at a height $(\mathrm{z})$ of $12 \mathrm{~m}$ and $17 \mathrm{~m}$ was obtained using eq. (9).

$$
u_{z}=u_{\text {obs. }}\left(\frac{\ln \mathbf{C} / z_{0}-}{\ln \mathbf{Q}_{\text {obs. }} / z_{0}}\right)
$$

where $u_{o b s}$ and $z_{o b s}$ are the wind speed and measurement height at the observation station (Oke, 2006). This will provide a basis for evaluating the loss of wind resource in urban areas.

\footnotetext{
${ }^{1}$ The illustration is with respect to a background wind reference $(A)$ of $5 \mathrm{~m} / \mathrm{s}$
} 
Table 2. Wind speed $(\mathrm{u})$ and wind direction (Dir) at the Airport $(\mathrm{A})$ background climate site where measurements are made at a height of $10 \mathrm{~m}$ above a grass surface and reported for each hour. The statistics include the mean and standard deviation of speed $\left(u_{M}\right.$ and $u_{S}$, respectively) and direction ( $\operatorname{Dir}_{M}$ and $\left.D \operatorname{Dir}_{S}\right)$. These statistics are provided for the entire dataset and for $30^{\circ}$ intervals of the compass direction ( $360^{\circ}$ is North). The final two columns represent estimated wind speed at $17 \mathrm{~m}$ and at $12 \mathrm{~m}$ at this site using the log wind profile.

\begin{tabular}{|c|c|c|c|c|c|c|c|}
\hline \multirow[b]{2}{*}{ Direction } & \multirow[b]{2}{*}{ Freq. } & \multicolumn{4}{|c|}{$A_{(10 \mathrm{~m}]}$} & \multirow{2}{*}{$\begin{array}{c}\boldsymbol{A}_{[17 \mathrm{~m}]} \\
\mathrm{u}_{\mathrm{M}}\end{array}$} & \multirow{2}{*}{$\begin{array}{c}\boldsymbol{A}_{\boldsymbol{( 1 2 \mathrm { m } ]}} \\
\mathrm{u}_{\mathrm{M}}\end{array}$} \\
\hline & & $\mathrm{u}_{\mathrm{M}}$ & $\mathrm{u}_{\mathrm{s}}$ & $\operatorname{Dir}_{M}$ & $u_{M}$ & & \\
\hline $0-30$ & $1.9 \%$ & 4.157 & 1.836 & 20.893 & 8.004 & 4.512 & 4.279 \\
\hline $30-60$ & $3.0 \%$ & 5.024 & 1.887 & 49.611 & 8.348 & 5.453 & 5.172 \\
\hline $60-90$ & $3.8 \%$ & 5.189 & 2.323 & 80.676 & 7.902 & 5.631 & 5.341 \\
\hline $90-120$ & $3.9 \%$ & 4.054 & 2.133 & 111.552 & 8.016 & 4.400 & 4.172 \\
\hline $120-150$ & $10.1 \%$ & 5.341 & 2.228 & 140.151 & 7.729 & 5.800 & 5.500 \\
\hline $150-180$ & $4.4 \%$ & 4.746 & 2.275 & 167.088 & 7.890 & 5.152 & 4.890 \\
\hline $180-210$ & $9.0 \%$ & 6.418 & 2.640 & 202.467 & 7.532 & 6.970 & 6.606 \\
\hline $210-240$ & $22.0 \%$ & 6.848 & 2.869 & 230.824 & 8.172 & 7.433 & 7.049 \\
\hline $240-270$ & $24.3 \%$ & 7.378 & 3.118 & 259.513 & 7.617 & 8.008 & 7.595 \\
\hline $270-300$ & $11.3 \%$ & 5.191 & 2.406 & 287.545 & 8.193 & 5.634 & 5.343 \\
\hline $300-330$ & $4.0 \%$ & 4.462 & 2.247 & 318.912 & 8.229 & 4.843 & 4.593 \\
\hline $330-360$ & $2.2 \%$ & 3.519 & 1.576 & 347.710 & 8.187 & 3.819 & 3.622 \\
\hline \multicolumn{2}{|c|}{ Summary (data set) } & 5.194 & 2.295 & 184.745 & 7.985 & 5.638 & 5.347 \\
\hline \multicolumn{2}{|c|}{ Summary $\left(120-300^{0}\right)^{*}$} & 5.987 & 2.589 & 214.598 & 7.856 & 6.500 & 6.164 \\
\hline
\end{tabular}

$120-300^{\circ}=81.1 \%$ of data

* $27^{\text {th }}$ of November 2010 to $9^{\text {th }}$ of December 2011

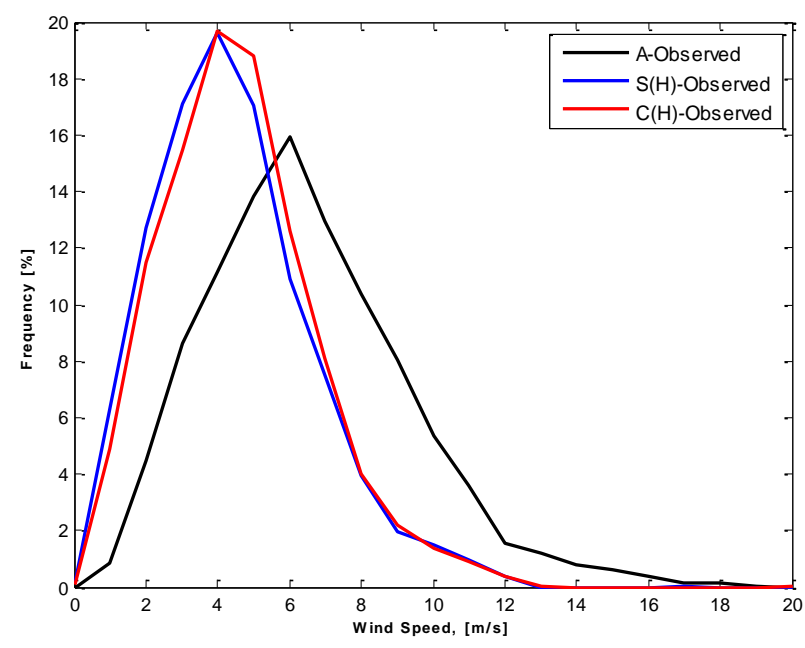

Figure 6: Frequency distribution of wind speeds observed at the urban (C) and suburban (S) high platforms with respect to the background airport (A) wind speed. Evident here is the diminished mean wind speeds presented at both $\mathrm{C}$ and $\mathrm{S}$ and the consistency in distribution presented at both locations.

\subsection{Wind observations at urban sites}

Table 3 presents the wind statistics for the high platform observations at $C_{H}$ and $S_{H}$ over the period corresponding to Airport data. The statistics are decomposed according to the $30^{\circ}$ sectors used for the Airport data in Table 2, to allow the reader to see the urban effect on both wind speed and direction. Firstly, the wind speed is diminished at both sites: by comparison with the estimated speed at the same height at the Airport, the mean wind speed at $\mathrm{C}_{H}$ and $\mathrm{S}_{\mathrm{H}}$ is $65 \%$ and $62 \%$. While the standard deviations are also smaller, the ratio to wind speed is higher than at the Airport. In other words, the wind speed is both lower in magnitude and proportionately more variable. The 
effect of urban roughness is also clear in the direction statistics, especially when the wind is from the less frequently occurring northerly sectors. Within the south-westerly sector $\left(120^{\circ}\right.$ to $\left.300^{\circ}\right)$ the mean wind direction at the Airport is $215^{\circ}$, while it is $217^{\circ}$ and $223^{\circ}$ at the two urban sites however, while the standard deviation at the Airport is $7.9^{\circ}$, the respective values for the urban sites are $25.9^{\circ}$ and $30.7^{\circ}$. Thus, while the average airflow direction at urban sites is broadly similar to that at the Airport in the sector where the wind resource is concentrated, it is less consistent. Figure 6 shows overall impact of urban roughness on the frequency distributions of measured wind at $C_{H}$ and $S_{H}$. Note that the effect is similar at both sites.

T able 3. Wind speed $(\mathrm{u})$ and wind direction (Dir) at the city $(\mathrm{C})$ and suburban (S) high platform sites. The statistics for each are decomposed according to the $30^{\circ}$ compass sectors as observed at the Airport site (Table 2).

\begin{tabular}{|c|c|c|c|c|c|c|c|c|}
\hline \multirow[b]{2}{*}{ Direction } & \multicolumn{4}{|c|}{$C_{H(17 m)}$} & \multicolumn{4}{|c|}{$S_{H(12 m)}$} \\
\hline & $u_{M}$ & $\mathrm{u}_{\mathrm{s}}$ & $\operatorname{Dir}_{M}$ & $\mathrm{Dir}_{\mathrm{S}}$ & $\mathrm{u}_{\mathrm{M}}$ & $\mathrm{u}_{\mathrm{s}}$ & $\operatorname{Dir}_{M}$ & $\mathrm{Dir}_{\mathrm{S}}$ \\
\hline $0-30$ & 2.253 & 1.002 & 81.805 & 86.141 & 1.909 & 0.934 & 103.701 & 86.009 \\
\hline $30-60$ & 3.260 & 1.527 & 75.999 & 45.857 & 2.434 & 1.045 & 91.338 & 47.388 \\
\hline $60-90$ & 4.120 & 1.753 & 90.856 & 34.358 & 3.009 & 1.313 & 103.208 & 42.498 \\
\hline $90-120$ & 3.331 & 1.835 & 113.245 & 41.832 & 2.846 & 1.624 & 127.011 & 50.533 \\
\hline $120-150$ & 3.620 & 1.798 & 138.836 & 41.625 & 3.386 & 1.860 & 151.121 & 48.828 \\
\hline $150-180$ & 3.411 & 1.662 & 166.984 & 38.715 & 3.713 & 1.792 & 179.452 & 36.993 \\
\hline $180-210$ & 4.875 & 2.204 & 211.382 & 26.120 & 5.166 & 2.427 & 217.531 & 26.852 \\
\hline $210-240$ & 5.011 & 2.167 & 239.409 & 17.843 & 5.031 & 2.173 & 243.527 & 23.180 \\
\hline $240-270$ & 5.091 & 2.114 & 263.330 & 14.392 & 4.759 & 2.086 & 267.632 & 18.382 \\
\hline $270-300$ & 3.860 & 1.762 & 281.550 & 16.689 & 3.442 & 1.615 & 281.440 & 30.160 \\
\hline $300-330$ & 3.044 & 1.613 & 286.764 & 45.008 & 2.650 & 1.395 & 286.359 & 55.358 \\
\hline $330-360$ & 2.214 & 0.928 & 231.193 & 117.284 & 2.105 & 1.082 & 218.875 & 114.950 \\
\hline $\begin{array}{l}\text { Summary } \\
\text { (data set) }\end{array}$ & 3.674 & 1.697 & 181.779 & 43.822 & 3.371 & 1.612 & 189.266 & 48.427 \\
\hline $\begin{array}{r}\text { Summary } \\
\left(120-300^{\circ}\right)^{*}\end{array}$ & 4.311 & 1.951 & 216.915 & 25.897 & 4.250 & 1.992 & 223.450 & 30.732 \\
\hline
\end{tabular}

* $27^{\text {th }}$ of November 2010 to $9^{\text {th }}$ of December 2011

Figure 7 shows a series of scattergrams representing the relationship between wind speed at each of the observation sites (Airport $(A), C_{H}, C_{L}, S_{H}, S_{L}$ ). The data shown here represent a shorter period $\left(28^{\text {th }}\right.$ November 2010 to $16^{\text {th }}$ January 2011) and is used here to show the strong relationship between the Airport and $\mathrm{C}_{\mathrm{H}}$ and $\mathrm{S}_{\mathrm{H}}$ sites. The relationship is considerably poorer at the lower level platforms which are positioned at near-roof height. While there is a strong correspondence between $S_{H}$ and $S_{L}$, that between $\mathrm{C}_{\mathrm{H}}$ and $\mathrm{C}_{\mathrm{L}}$ is quite weak. We may speculate that the reason for this difference is due to the distance between sites (circa $500 \mathrm{~m}$ in the City) and the placement of the instrument at the gable end of a house with a hipped roof, which is likely to generate considerable turbulence. The majority of the focus in the following discussion is on the wind resource well above roof height $\left(\mathrm{C}_{\mathrm{H}}\right.$ and $S_{H}$ ). 


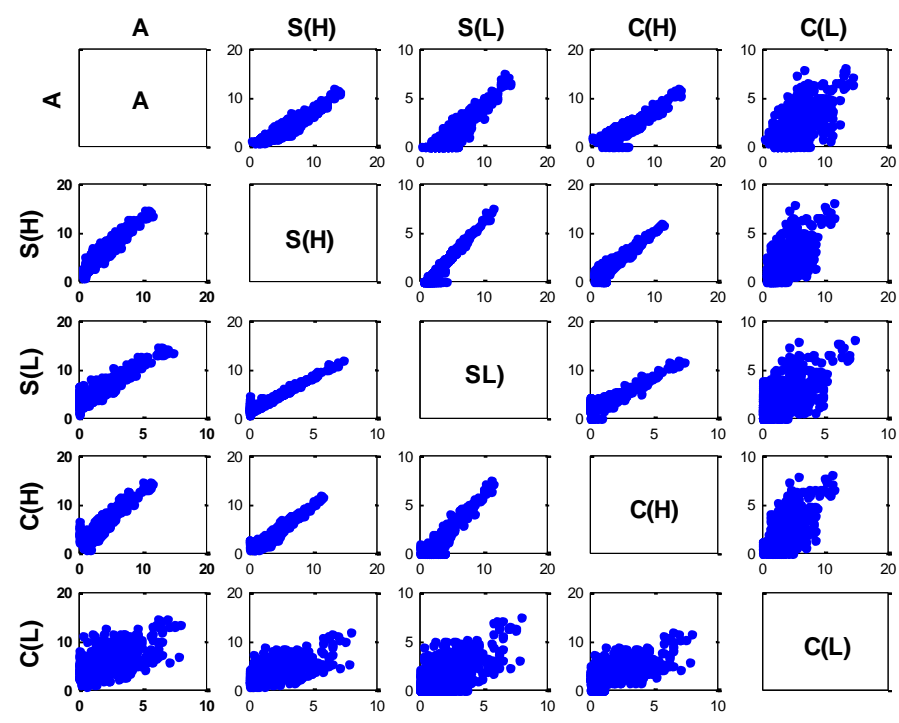

Figure 7: Relationships between observed wind speeds at upper and lower platform positions at both the suburban (s) and urban (C) locations with respect to the Airport (background) observations. The scatter-grams illustrate the good correlation between the background and upper platforms and the marked deterioration in low-platform comparisons.

\subsection{Estimating urban wind speed}

Table 4 illustrates the results of the three methods (Wieranga, Bottema and Log) used here to estimate wind speed at the high platform urban sites, that is above the urban RSL $\left(z \geq z^{*}\right)$. Each method requires knowledge of the roughness length $\left(z_{0}\right)$, which in the case of applying Wieranga and Bottema was obtained from Table 1, based on Davenport's classification. The selected values of 0.55 and $1.15 \mathrm{~m}$ representing the suburban and city sites respectively are the average values for that landscape. The friction velocity $\left(u_{*}\right)$ in the Bottema approach is based on the ratio of urban to rural values ( $\beta$ in eq. (4)). Finally in the log model, both $z_{0}$ and $u *$ are determined by fitting the log profile to the measured wind at the urban sites. Overall, Wieranga overestimates the mean wind speed (by $8 \%$ at $\mathrm{C}_{\mathrm{H}}$ and $12 \%$ at $\mathrm{S}_{\mathrm{H}}$ ) while Bottema underestimates (by $29 \%$ and $20 \%$ ). Two measures of model fit are presented: the Mean Absolute Error (MAE) and the Root Mean Square Error (RMSE). The value of each was smaller for Wieranga at both sites and the difference was most pronounced for the city location.

Table 4: Estimated wind-speed at the high platform at the City $\left(\mathrm{C}_{\mathrm{H}}\right)$ and Suburban $\left(\mathrm{S}_{\mathrm{H}}\right)$ sites using the logarithmic wind profile adjusted according to Wieranga (eq. (3)), Bottema (eq. (4)) and based on a fit to observed data. The measures of goodness of fit are the Mean Absolute Error (MAE) and the Root Mean Square Error (RMSE).

\begin{tabular}{|c|c|c|c|c|c|c|c|c|}
\hline \multirow[b]{3}{*}{ Roughness } & \multicolumn{4}{|c|}{$C_{H}$} & \multicolumn{4}{|c|}{$S_{H}$} \\
\hline & Observed & $\begin{array}{c}\text { Wieranga } \\
\text { Model }\end{array}$ & $\begin{array}{c}\text { Bottema } \\
\text { Model }\end{array}$ & Log-Model & Observed & $\begin{array}{c}\text { Wieranga } \\
\text { Model }\end{array}$ & $\begin{array}{c}\text { Bottema } \\
\text { Model }\end{array}$ & Log-Model \\
\hline & -- & 1.15 & 1.15 & 0.8713 & -- & 0.55 & 0.55 & 0.5171 \\
\hline $\begin{array}{c}\text { Friction } \\
\text { velocity ratio }\end{array}$ & -- & 1.0 & 1.3312 & 1.7022 & -- & 1.0 & 1.2636 & 1.5512 \\
\hline$u_{M}[\mathrm{~m} / \mathrm{s}]$ & 4.5992 & 4.9728 & 3.2281 & 4.6165 & 4.4401 & 4.9804 & 3.5795 & 4.3940 \\
\hline$u_{s}[\mathrm{~m} / \mathrm{s}]$ & 2.1288 & 2.2497 & 1.4604 & 2.0885 & 2.1712 & 2.2269 & 1.6005 & 1.9647 \\
\hline $\operatorname{MAE}[\mathrm{m} / \mathrm{s}]$ & -- & 0.7113 & 1.4248 & 0.6133 & -- & 0.9392 & 1.0635 & 0.7594 \\
\hline$R M S E[\mathrm{~m} / \mathrm{s}]$ & -- & 0.9790 & 1.6878 & 0.8651 & -- & 1.2202 & 1.3873 & 1.0479 \\
\hline
\end{tabular}


Not surprisingly the fitted Log model provided the best overall fit. The model parameters are estimated using observed Airport winds between $120^{\circ}$ and $300^{\circ}$, which contains $81 \%$ of the records. The estimated $z_{0}$ at the city and suburb sites is 0.87 and $0.52 \mathrm{~m}$. Both of these values are within the range of roughness associated with each landscape (Table 1 ), but are on the low end (especially for the city site). This $z_{0}$ value represents an average for the urban landscape, weighted by the frequency of wind from a given direction. The ratio of the friction velocity at the urban sites, when compared to the rural site, was 1.70 and 1.55 , respectively. These values are higher than that suggested by Bottema however, this may be expected given that the value of $\beta$ in eq. (4) was acquired from wind tunnel experiments using block like obstacles. In the city, the great variation in roughness elements and their placement is likely to exert a stronger drag on the overlying atmosphere. These results indicate that, in the absence of measured values of surface roughness, the existing models produce significant errors in the mean wind speed and in assessing the potential wind resource.

Table 5 presents the comparison of the observations at $\mathrm{S}_{\mathrm{L}}$ and $\mathrm{C}_{\mathrm{L}}$ (over the shorter period from the 28th November 2010 to 16th January) to modelled wind speed using the Power Law (eq. (7)), the COST approach (eq. (8)) using Bottema's adjustment for friction velocity (eq. (4)) and, the COST approach using the friction velocity obtained from the fitted Log model above. The results for the low platform City site are especially poor with the mean and standard deviation values consistently underestimated. The results for $S_{L}$ are somewhat better but the error terms are also large compared to the measured wind resource and the measured coefficient of variation $\left(u_{M} / u_{S}\right)$ is 0.9 for the observations, but is over 2.0 for the estimates. These results do not provide any confidence in our ability data to assess the wind resource at this level.

Table 5: Estimated wind-speed at the low platform at the City $\left(\mathrm{C}_{\mathrm{L}}\right)$ and Suburban $\left(\mathrm{S}_{\mathrm{L}}\right)$ sites using the Power Law (eq. (6)) and COST (eq. (5)) methods. The difference between COST and COST fitted is that the latter uses a friction velocity value at the top of the RSL that is based on the Bottema adjustment (eq.(4)), while the fitted scheme acquires $u_{*}$ from the log-model employed in Table 5. The measures of goodness of fit are the Mean Absolute Error (MAE) and the Root Mean Square Error (RMSE).

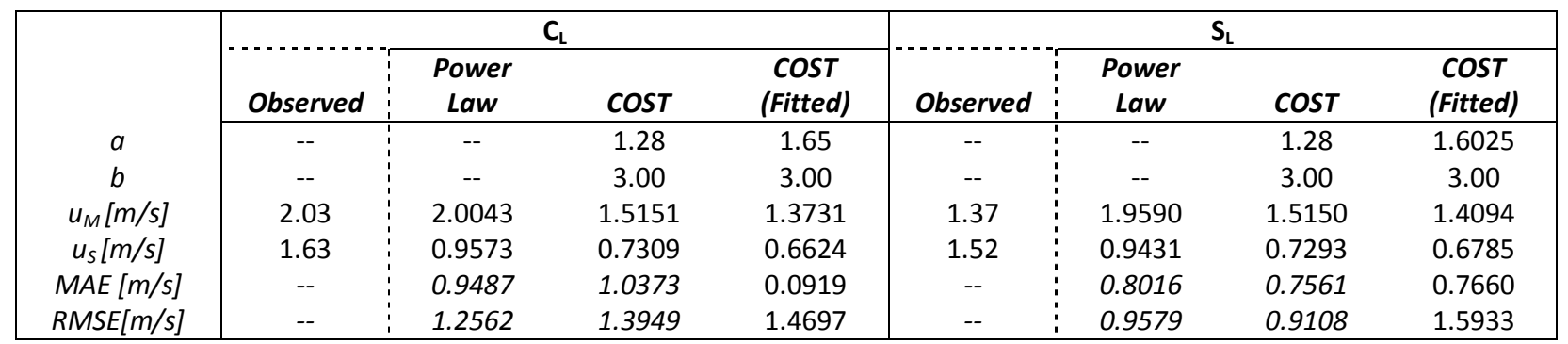

\section{Discussion}

Ideally, in assessing the potential wind resource at different urban sites, one could make use of observations made at a standard meteorological station and adjust these to suit a selected site. Work on the urban wind field, completed primarily for the purpose of air quality modelling, has shown that this adjustment is not straight-forward owing to the rough nature of the urban surface that creates a deep Roughness Sub-layer that is between 1.5 and 4 times the mean height of the roughness elements. Observations above the RSL may be transferred to other sites using the logwind profile, once the surface roughness length is known. However, employing standard tabulated values is likely to result in significant over(under)estimation of the wind-speed. Moreover, the results here suggest that the friction velocity also cannot be taken as constant between the two sites. Using the existing techniques of Wieranga and Bottema and employing tabled roughness values produced biased estimates indicating that site specific knowledge of the surrounding urban 
morphology is needed. Here, the parameters of the log profile $\left(z_{0}\right.$ and $\left.u_{*}\right)$ were obtained by fitting the profile to observed wind-speed at the level of the measurement platforms $\left(z^{*}\right)$. This profile was constrained by establishing a boundary condition at a level well above the roughness elements, based on extrapolating the measurements made at an Airport site using a log profile. The resulting model describes the observations closely. Figure 8 plots the observed against the estimated windspeed at both the urban and suburban sites - the coefficients of determination $\left(r^{2}\right)$ are 0.92 and 0.88 , respectively. Note that the scatter of points is consistent across the range of observations.

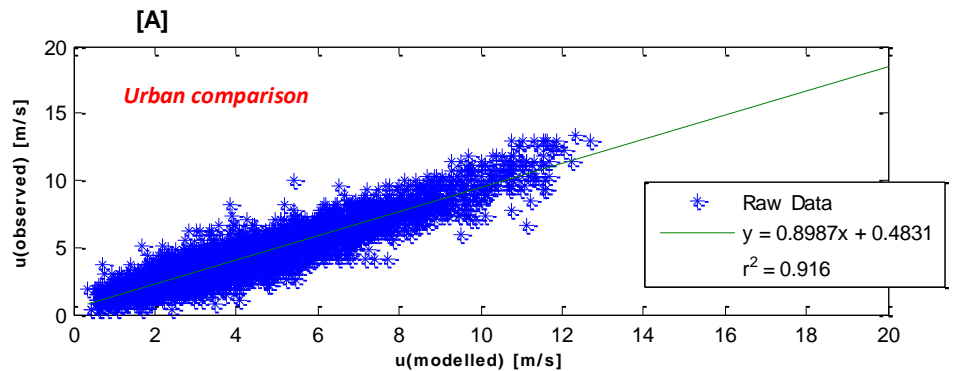

[B]

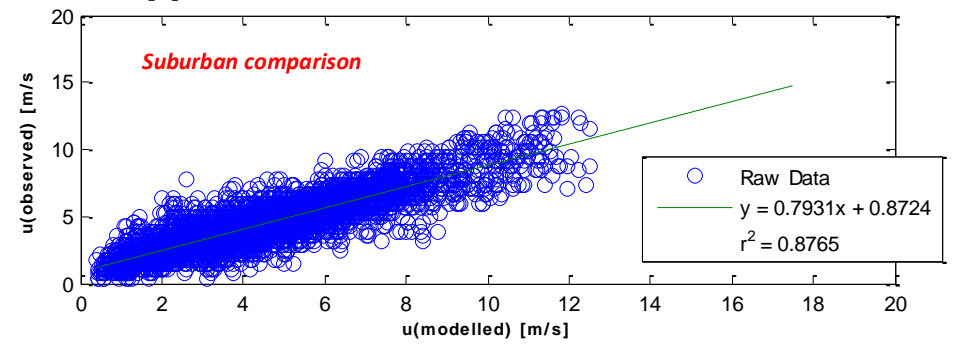

Figure 8: Scatter-grams comparing the (high-platform) observed and modelled wind speed ( $28^{\text {th }}$ November 2010 to $16^{\text {th }}$ January 2011). A strong relationship is evident with high goodness of fit $\left(r^{2}\right.$ being 0.92 and 0.88 for the urban [A] and suburban $[B]$ locations respectively) and the associated scatter of points are consistent across the range of observations.

An objective of this research is to determine if there is a predictable wind resource in an urban area that is worth harnessing. To evaluate this we estimate the output of a micro wind turbine that is positioned at the level of the high platforms at the urban $(17 \mathrm{~m})$ and suburban $(12 \mathrm{~m})$ sites. The Wind Energy Solutions' (WES ${ }^{5}$ ) Tulipo turbine is used as appropriate technology. It has a cut-in wind speed of $3 \mathrm{~m} / \mathrm{s}$ (ideal for urban locations) and can produce $2.5 \mathrm{~kW}$ from its associated $5 \mathrm{~m}$ (diameter) blades at a rated wind speed of $9 \mathrm{~m} / \mathrm{s}$ (Wind Energy Solutions, 2011). The results based on observations are shown in Table 6. At the Airport site, the turbine averages $1.06 \mathrm{~kW}$ and over the period, the capacity factor was observed to be $42 \%$. Over the course of a year, it could generate in excess of $5892 \mathrm{kWh}$, which exceeds the average domestic (electrical) energy demand in Ireland (approx. $5000 \mathrm{kWh}$ ). At the city and suburban site, the lower mean wind-speeds results in a reduced output: $2445 \mathrm{kWh}$ and $2672 \mathrm{kWh}$, respectively. Moreover, for both sites the capacity factor was halved to $20 \%$. Nevertheless, these values still represent half of the domestic energy demand. In Table 7, the frequency distribution of energy generation is shown for all three observation sites based on the recorded hourly wind-speeds. Not surprisingly, the urban sites have higher frequencies at the lower end of energy output, which shows the effects of surface roughness (see Figure 6). The slowing of wind has a non-linear and significant impact on energy generation (see eq. (1)). Allen et $a$ l (2008) in their analysis of the performance of a wind turbine located in varying geographical locations (urban and rural) also observed that the height positioning of the turbine, by virtue of the cubic relationship associated with wind speed, significantly affects the energy harnessing of such technologies. 
Table 6: Micro wind turbine potential at the Airport, City $\left(\mathrm{C}_{H}\right)$ and Suburb $\left(\mathrm{S}_{H}\right)$ sites based on observations. The technology employed is the WES(5) Tulipo, which has a rated speed at $9 \mathrm{~m} / \mathrm{s}$ when it generates $2.5 \mathrm{~kW}$. The capacity factor indicates the proportion of occasions that the turbine is at rated output

\begin{tabular}{|lccc|}
\hline Property & Airport & $\boldsymbol{C}_{\boldsymbol{H}}$ & $\boldsymbol{S}_{\boldsymbol{H}}$ \\
\hline $\mathrm{u}_{\mathrm{M}}[\mathrm{m} / \mathrm{s}]$ & 6.43 & 4.60 & 4.44 \\
$\mathrm{u}_{\mathrm{S}}[\mathrm{m} / \mathrm{s}]$ & 2.87 & 2.13 & 2.17 \\
Energy $[\mathrm{kWh}]$ & 5892.13 & 2445.53 & 2672.70 \\
Power $_{\text {(average) }}[\mathrm{kW}]$ & 1.06 & 0.51 & 0.48 \\
Capacity Factor $[\%]$ & 42.42 & 20.43 & 19.24 \\
\hline
\end{tabular}

As a test of the model developed in this paper, the energy generated by the Tupilo turbine using observed and estimated wind at the City and Suburb sites was calculated. Although the wind-speeds are well matched (Figure 7), the cubic relationship with power contained in eq. (1) means that comparing estimates of energy generation based on observed and predicted winds is less straightforward. Here we assessed the ability of the modeled winds to match the observed frequency distributions presented in Table 7. At the suburban site, the model predicted the correct power category $59 \%$ of the time and on $27 \%$ of occasions was one category higher or lower. In other words, the model can predict the energy output with a precision of $+/-0.25 \mathrm{~kW}$, with $86 \%$ confidence. At the city site the model correctly predicted the power category on $63 \%$ of occasions and its predictions were correct within a band of $+/-0.25 \mathrm{~kW}$, with $90 \%$ confidence. In summary then, the log-wind model can provide an accurate assessment of the wind resource above roof height once its parameters are known with sufficient precision.

Table 7: Average turbine generator output $(\mathrm{kW})$ using observed and modelled wind speed at the City $\left(\mathrm{C}_{\mathrm{H}}\right)$ and Suburb $\left(\mathrm{S}_{\mathrm{H}}\right)$ sites. Turbine output has been categorised into 10 ranges and the average output at each site is tabulated.

\begin{tabular}{|c|cc|cc|cc|}
\hline $\begin{array}{c}\text { Turbine output } \\
\text { Bin range }(\boldsymbol{k W})\end{array}$ & $\boldsymbol{3}$ Airport & \multicolumn{2}{c|}{ City high platform } & \multicolumn{2}{c|}{ Suburb high platform } \\
Measured & $\boldsymbol{N}$ & Measured & $\boldsymbol{N}$ & 0.08 \\
\hline $0.00-0.25$ & 1391 & 0.11 & 2145 & 0.07 & 2722 & 0.36 \\
$0.25-0.50$ & 771 & 0.40 & 1050 & 0.36 & 1135 & 0.61 \\
$0.50-0.75$ & 462 & 0.62 & 518 & 0.61 & 534 & 0.86 \\
$0.75-1.00$ & 422 & 0.81 & 307 & 0.87 & 332 & 1.12 \\
$1.00-1.25$ & 377 & 1.03 & 229 & 1.11 & 213 & 1.36 \\
$1.25-1.50$ & 345 & 0.00 & 130 & 1.37 & 159 & 1.61 \\
$1.50-1.75$ & 309 & 1.58 & 91 & 1.60 & 102 & 1.88 \\
$1.75-2.00$ & 277 & 1.91 & 65 & 1.87 & 67 & 2.13 \\
$2.00-2.25$ & $0 *$ & 0.00 & 47 & 2.11 & 51 & 2.48 \\
$2.25-2.50$ & 1201 & 2.46 & 207 & 2.48 & 241 & \\
\hline
\end{tabular}

*Airport wind speeds are in knots and normalized to $\mathrm{m} / \mathrm{s}$.

Finally, we might consider how the wind resource becomes depleted as the turbine is moved downwards, closer to roof level. Our observation data does not allow us to explore this region so we must rely on the available models to extrapolate from the predicted wind at the high platform levels $\left(z^{*}\right)$ into this zone. Figure 9 shows how generator productivity diminishes with height: at $0.7 z^{*}$ the energy capture capability has dropped by almost half at both sites. This demonstrates the sensitivity of the wind resource in this region. This result can be translated into economic terms using rudimentary information on the cost of the turbine system and the expected income that arises (either by offsetting external energy sources or by export to a grid) from energy generation. Assume that the cost for wind turbine system, such as that described above, is about $€ 14,500$ (SECO, 2012) and the energy income rate is $€ 0.25$ per $\mathrm{kWh}$. Using annualized wind speeds at $\mathrm{z}^{*}$ (that is, the height of $C_{H}(17 \mathrm{~m})$ and $\mathrm{S}_{\mathrm{H}}(12 \mathrm{~m})$ ) and sample consumer load (RMDS, 2012), we estimate that the turbine cost is recovered within 13.1 and 14.8 years, respectively. However, at $0.7 \mathrm{z}^{*}$ (that is, about $2.5 \mathrm{~m}$ and $1.5 \mathrm{~m}$ lower than $\mathrm{C}_{\mathrm{H}}$ and $\mathrm{S}_{\mathrm{H}}$ ), the time taken to recover the initial investment is doubled. Clearly, the vertical placement of the turbine within the urban environment is critical. 

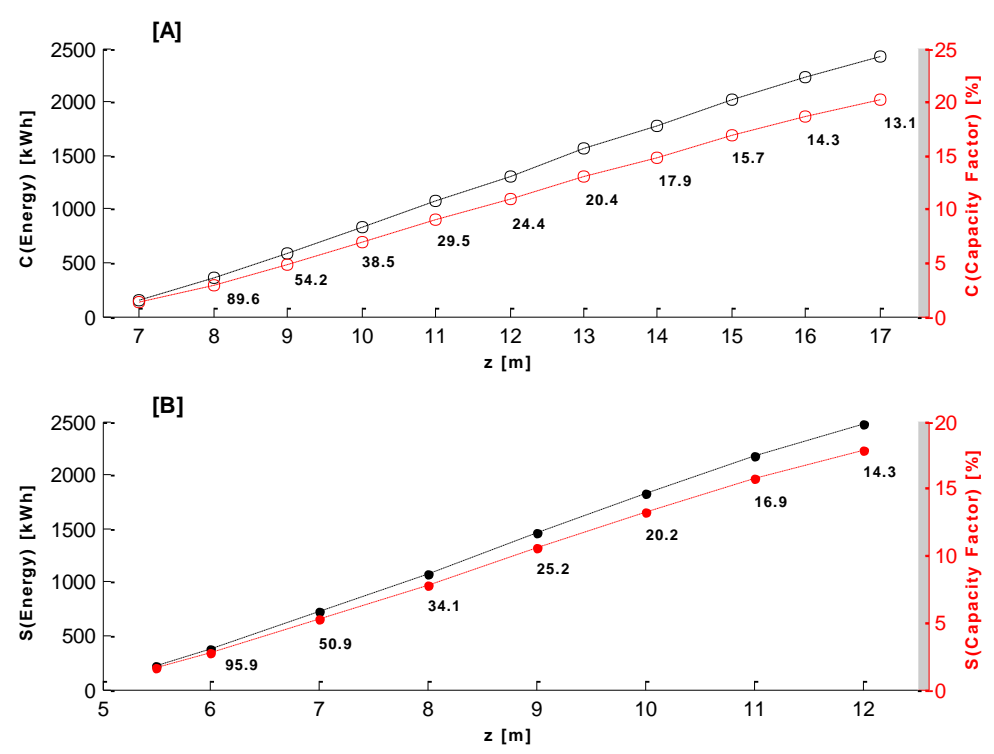

Figure 9: Illustrating the effect on the wind generator (WE (Tulipo), $2.5[\mathrm{~kW}])$ at both the urban $[\mathrm{A}]$ and suburban $[\mathrm{B}]$ locations. The diminished productivity is expressed in terms of energy production ( $\mathrm{kWh}$ ) and capacity factor (\%). The wind resource output sensitivity to height is further considered economically. For each height between $z_{d}$ and $z^{*}$ at both locations, the simple payback (energy savings expressed as a factor of turbine system capital costs is presented for a consumption/export rate of $€ 0.25$.

\section{Summary and Conclusions}

The primary focus of this paper was to investigate whether the wind resource above a city surface could be predicted from wind observations made at a nearby site, such as those available at conventional meteorological weather station. The availability of high quality wind observations in Dublin has allowed us to test several different approaches to transferring data gathered at an Airport site to two urban locations representing a city centre and a suburban site. Both urban sites are positioned at between 1.5 to 2 times the mean height of buildings and are taken to be above the roughness sub-layer $\left(z^{*}\right)$. The results indicate that a simple log-profile model performs very well but that the selection of parameter values (roughness length and friction velocity) is critical. In the case reported here, using tabled values without a detailed examination of the urban landscape around the observation sites resulted in significant errors of bias. The availability of wind observations in this study allowed us to obtain the values for the parameters precisely. Future research will focus on obtaining these parameters by urban morphological analysis, independently of wind measurements.

A suitably parameterised log model has been shown to provide consistently good predictions of the urban wind resource at $z^{*}$ and of the energy potential at this level. However, this would place the turbine well above the height of the buildings which is unacceptable in many current planning environments (although this may change). Unfortunately, there are few studies on the wind profile in the layer between roof-height and $z^{*}$ and our observations at near roof level do not provide a basis for evaluating existing models, which have been developed primarily for air quality purposes. Using the estimated wind speed at $z^{*}$, these models indicate a rapid decline in the energy generation capacity and a corresponding increase in the time taken to recover the initial investment. This work indicates that it is possible to provide guidelines for the correct placement of micro-turbines in urban environments and that their potential for energy generation and cost recovery are predictable. The next stage of this research will be to develop a suitable description of the urban 
landscape that can be used to estimate model parameters with sufficient precision so that the wind resource can be assessed a priori from background meteorological observations.

\section{Acknowledgements}

The authors would like to thank Dr. Rowan Fealy of National University of Ireland Maynooth (NUIM) and colleagues (Paul Alexander and Stephanie Keogh) within the Dublin Urban Boundary Layer Experiment (DUBLex), for graciously providing the data used in this research 


\section{REFERENCES}

ALLEN, S.R., G.P. Hammond, and McManus, M.C., 2008. 'Energy analysis and environmental life cycle assessment of a micro-wind turbine', Proc. Instn Mech. Engrs Part A: Journal of Power and Energy, 222 (7): 669-684 [DOI: 10.1243/09576509JPE538]

AYHAN, D. \& SAĞLAM, Ş. 2012. A technical review of building-mounted wind power systems and a sample simulation model. Renewable and Sustainable Energy Reviews, 16, 1040-1049.

BAHAJ, A. S., MYERS, L. \& JAMES, P. A. B. 2007. Urban energy generation: Influence of micro-wind turbine output on electricity consumption in buildings. Energy and Buildings, 39, 154-165.

BOTTEMA, M. 1995. Aerodynamic Roughness Parameters for Homogeneous Building Groups. Lab. de Mécanique des Fluides.

BOTTEMA, M. 1997. Urban roughness modelling in relation to pollutant dispersion Atmospheric Environment, Vol. 31, No. 18. (1997), pp. 3059-3075. Key: citeulike:9469795.

CABELLO, M. \& ORZA, J. A. G. 2010. Wind speed analysis in the province of Alicante, Spain. Potential for small-scale wind turbines. Renewable and Sustainable Energy Reviews, 14, 3185-3191.

CAMPBELL-SCIENTIFIC. 2011. CSAT3 3-D Sonic Anemometer [Online]. Available: http://www.campbellsci.com/csat3 [Accessed].

CENELEC 2007. EN 50438 - Requirements for the connection of micro-generators in parallel with public low-voltage distribution networks.

DEPARTMENT OF ENVIRONMENT, C. A. L. G. 2011. BUILDING REGULATIONS (PART L AMENDMENT) REGULATIONS 2011. S.I. No. 259 of 2011. Ireland.

DE WIT, M. H., STATHOPOULOS, T. \& WISSE, J. A. 2002. Airport wind speeds used for the design in urban environments: the Eindhoven case. Journal of Wind Engineering and Industrial Aerodynamics, 90, 1289-1298.

ENCRAFT. 2008. Warrick Wind Trials: Final Report. UK.

EST 2009. Location, Location, Location: Domestic small-scale wind field trial report. Energy Savings Trust.

FISHER, B. E. A., JOFFRE, S., KUKKONEN, J., PIRINGER, M., ROTACH, M., SCHATZMANN, M. 2005. RE: Meteorology Applied to Urban Air Pollution Problems. Final Report of COST Action 715.

FYRIPPIS, I., AXAOPOULOS, P. J. \& PANAYIOTOU, G. 2010. Wind energy potential assessment in Naxos Island, Greece. Applied Energy, 87, 577-586.

GOOGLE EARTH 2010. Locations of the wind observations across Dublin City [online] Available through: URL. [Accessed 10th November 2012].

HEATH MA, WALSHE JD \& WATSON SJ. 2007. Estimating the potential yield of small buildingmounted wind turbines. Wind Energy, 10, 271-287. 
ISLAM, M. R., SAIDUR, R. \& RAHIM, N. A. 2011. Assessment of wind energy potentiality at Kudat and Labuan, Malaysia using Weibull distribution function. Energy, 36, 985-992.

JOWDER, F. A. L. 2009. Wind power analysis and site matching of wind turbine generators in Kingdom of Bahrain. Applied Energy, 86, 538-545.

KAVAK AKPINAR, E. \& AKPINAR, S. 2005. A statistical analysis of wind speed data used in installation of wind energy conversion systems. Energy Conversion and Management, 46, 515-532.

MACDONALD, R. W., GRIFFITHS, R. F. \& HALL, D. J. 1998. An improved method for the estimation of surface roughness of obstacle arrays - a comparative study of the land use and built form of 110 schemes. Atmospheric Environment, 32, 1857-1864.

MACDONALD, R. 2000. Modelling the mean velocity profile in the urban canopy layer. BoundaryLayer Meteorology, 97, 24-45.

MILLWARD-HOPKINS, J. T., TOMLIN, A. S., MA, L., INGHAM, D. \& POURKASHANIAN, M. 2011. The predictability of above roof wind resource in the urban roughness sublayer. Wind Energy, n/a-n/a.

NOABL. 2012. Wind Speed Database [Online]. Department of Energy \& Climate Change. Available: http://www.decc.gov.uk/en/content/cms/meeting_energy/wind/windsp_databas/windsp_databas. aspx [Accessed].

OFFICIAL JOURNAL OF THE EUROPEAN UNION 2010. DIRECTIVE 2010/31/EU OF THE EUROPEAN PARLIAMENT AND OF THE COUNCIL on the energy performance of buildings (recast). In: COUNCIL, E. P. A. (ed.) 2010/31/EU.

OKE, T. R. 2006. Initial guidance to obtain representative meteorological observations at urban sites. In: WMO/TD (ed.) Instruments and Observation Methods Report No. 81.

PEACOCK, A. D., JENKINS, D., AHADZI, M., BERRY, A. \& TURAN, S. 2008. Micro wind turbines in the UK domestic sector. Energy and Buildings, 40, 1324-1333.

PLANNING AND DEVELOPMENT REGULATIONS 2007. Ireland: Department of the Environment, Heritage and Local Government.

PORTAL, P. 2011. Wind Turbines - Planning Permission [Online]. Available: http://www.planningportal.gov.uk/permission/commonprojects/windturbines/ [Accessed 10th May 2012].

Retail Market Design Service (RMDS), Standard Load Profiles [Online] Available: http://www.rmdservice.com/guidance/standard_load_profiles.htm [Accessed August, 2012]

RAUPACH, M. R. 1994. Simplified expressions for vegetation roughness length and zero-plane displacement as functions of canopy height and area index. Boundary-Layer Meteorology, 71, 211216.

ROTACH M.W., VOGT R., BERNHOFER C., BATHVAROVA E., CHRISTEN A., CLAPPIER A., FEDDERSEN B., GRYNING S.-E., MARTUCCI G., MAYER H., MITEC V., OKE T.R., PARLOW E., RICHNER H., ROTH M., 
ROULET Y.-A., RUFFIEUX D., SALMOND J.A., SCHATZMANN M. \& J.A, V. 2005. BUBBLE - an Urban Boundary Layer Meteorology. Theoretical and Applied Climatology.

SECO. Small Wind Systems. [on-line] 2012 [cited 2012 27th July]; Available from: http://www.seco.cpa.state.tx.us/re_wind_smallwind.htm.

WATSON S., I. D., HARDING M. 2007. Predicting the Performance of Small Wind Turbines in the RoofTop Urban Environment,.

WES WIND ENERGY SOLUTIONS. 2011. WES(5) Tulipo [Online]. Available: http://www.cellenergy.ie/pdf/WES5_Tulipo_brochure_ds1.pdf [Accessed 10th October 2012].

WIERINGA, J., 1986: Roughness-dependent geographical interpolation of surface wind speed averages. Quarterly Journal Royal Meteorological Society, 112, pp. 867-889. 